\title{
Energy Factor of Coal Mining Region Sustainable Development
}

\author{
Valeriy Kopein ${ }^{1}$, Elena Filimonova ${ }^{1}$, Irina Kudryashova ${ }^{1,{ }^{*}}$, and Ksenia Demidenko ${ }^{1}$ \\ ${ }^{1}$ Plekhanov Russian University of Economics, Kemerovo branch, 650992, pr. Kuznetskiy, 39, \\ Kemerovo, Russia
}

\begin{abstract}
Economic sanctions as well as geopolitical situation have set new challenges for Russia. They reflect the necessity of creating an economy that is resistant to both the impact of external, often negative factors, and the need to reformat domestic economic policies. The article deals with the features of the interconnection of the industrial region energy sector and the sustainability of its development. It emphasizes the fact that in the context of an economic crisis the adaptation of regions to new economic conditions is actively influenced by internal factors. The fuel and energy complex is becoming one of the leading domestic resources as well as a catalyst for the related industries. It is noted that unsustainable processes of activating internal regional resources (energy, finance, etc.) hinder achieving sustainable development of the economy.
\end{abstract}

\section{Introduction}

Since 2014, and in fact - much earlier, Russia is in conditions that demonstrate the unpreparedness and inability of the old model of economic development to adequately meet the challenges of the time. Assessment of the consequences of economic sanctions for Russia is carried out by many scientists, practitioners, and experts.

Their beliefs often differ widely. But it can be concluded that the Russian economy is sensitive to external influence, which is noted by many specialists $[1,2,3]$. At the same time, export oriented raw materials economy in Russia is being destroyed and a new model is being searched for. A special role in these processes is assigned to the process of import substitution in all sectors. The import substitution, defined as the strategic line of Russia's development for the coming years, has become fruitful. Agriculture is improving successfully. But to assess the results of economic sanctions imposed on Russia and its retaliatory actions (embargoes) positively may seem too optimistic.

Researchers note that the embargo effect was blurred by devaluation of national currency (ruble), decline in household incomes, which led to consumers' denial of more expensive imported products. The adaptation processes in single-industry economy regions with predomination of extractive industries is particularly tough [4, 5, 6, 7]. A distinctive feature of activating existing production is a lack of investments in new production. Economic sanctions have exacerbated the processes of technological renewal, since a large

\footnotetext{
* Corresponding author: kudrina2007@mail.ru
} 
number of industries remain dependent on foreign suppliers to a large extent $[8,9]$. This is relevant for the fuel and energy industry, as well as mining enterprises [10]. The search for the possible autonomy of the region is complicated by the inability to localize financial resources and electricity in the administrative borders of the region. There is no clear indication which funds are specifically the finances of the region. This is also true for energy resources, since each region is a part of the country's energy system and the region with the scarcity of energy are supplied by other territories that produce it in abundance. Thus, scientists and experts face the high-level research task of determining the selfsufficiency of every region. These aspects determine the relevance of the problems considered in this article.

\section{Materials and methods}

The methodology of the study is largely formed in the classical version of the economic phenomena study dividing them into two levels of knowledge - empirical and theoretical. Such an approach is inherent in the understanding of processes and phenomena as interrelating and constantly developing system elements. Gnosiologically, this corresponds to a dialectical view of the nature of things and phenomena of a general order. The study of the interrelationships of various sectors of the national economy requires the use of statistical and econometric methods that allow us to formalize the trends that are being identified. Formation of an empirical base of research requires processing of statistical data that allows making a comparison and generalization, and thus moving to a higher level of knowledge. The use of the method of moving from the abstract to the concrete reveals the essence of high-level phenomena: interrelationship of production technology in industries, sustainability of economic development and the security problems of the region as a whole.

The object of the study is the region in which economy, budget, and social environment are formed by extractive industries, fuel and energy complex. The subject of the study is the interconnection of the fuel and energy complex and the stability of the overall development dynamics.

Application of the historical method is based on the axiomatic acceptance of the evolutionary development of the economy. This characterizes the dialectical approach, which is unquestionably the only scientific approach to studying phenomena in dynamics. The chronological period of the study is 2013-2017. This period is taken under consideration due to the fact that it is most indicative for covering the issues of sustainability of economic development in the conditions of economic instability. The connection of the research with the phases of the global economic crisis reflects the link between economic and political tensions and the aggravation of the situation in the world and in regions. In our opinion, in order to obtain reliable scientific knowledge applying historical and evolutionary methods is justified.

Employing the methods of abstraction, analysis and synthesis to the theoretical level of cognition helps to generalize the empirical data and to identify the most significant features without reducing the overall accuracy. Starting from the axiom that the problems of sustainable development are in correlation with the identifying and managing various factors, the system concept helps to move from assessing the technological level of the fuel and energy complex to its impact on the stability and security of the region.

\section{Results and discussion}

Countries with developed economies directly or indirectly set the rules in the markets, clearly defining who "drives" and who is "driven". At the same time, a country that 
produces unique, technically advanced products can become a "driver". If a market entity supplies a product which is abundant in the market or not technologically unique or valued, it becomes a hostage to the situation, without being able to influence it. Ultimately, the country's level of technical and technological development determines its rank in the world system and the opportunity to receive all the benefits of equal cooperation with other countries and regions.

Energy is the basis for production, and if there is a lack of it, one can hardly expect full capacity operation development of the production forces. Dependence of the coal-mining region on the raw material market leads to the dependence of the region's energy security on external factors, primarily on prices and the balance of supply and demand. At present the Kemerovo region's energy production is declining, whereas its consumption is increasing. It is dictated by several reasons, some of which are related to the technology of wholesale market electricity supply, others to crisis phenomena and decline in production.

Economic crisis is a painful but, in its own way, positive phenomenon. Regions, industries, and enterprises have to look for means of economic survival which are related to production, business and management efficiency. In the Kemerovo region, as well as in other problematic regions, it is necessary to create conditions for a fundamentally new implementation of the industrial potential, which is ascending from being an extractive region to a region of high technologies based on the production of electric and thermal energy. This process is inseparably connected with the demand for innovation as well as scientific and technological progress. The task of integrating coal mining and energy production has become the most critical task of the integrated development of the Kuzbass industry. This idea is not innovative. During several decades, much has been said and written about the need for advanced processing of coal which would result in obtaining products of high added value - gasoline, sorbents, etc. Progress in this direction has already been made, but this work is still far from being called systematic.

The increase in generating and selling electricity to other regions is of particular interest. The demand in electricity is growing, and the Kemerovo region has high potential in its generating. The process is not indisputably positive, however, since coal mining, which has been expanding for the last decade, resulted in increasing environmental and social challenges in the region.

In Russia, generation of electricity with the use of coal is decreasing from year to year and at present it comprises less than $30 \%$. In advanced economies coal dominates in the fuel balance: in the United States its share is $55 \%$, in European countries $-40-60 \%$, in Poland - over $90 \%$. In Russia there are almost 600 thermal plants, including 56 of gas-andoil-based plants, 27 of which retain all technologies and infrastructure for coal operating. These federal plants can be converted for operating on the basis of coal.

Using coal as the main fuel for thermal and electric power plants is necessary and it can be carried out on the basis of new technologies meeting the high standards of pollution protection. At present, in the Kemerovo region, as well as in other regions of Russia, fuel is used inefficiently. In Europe, for example, in order to produce a Gcal of energy even lowpower boilers do not exceed specific fuel consumption of $200 \mathrm{~kg}$, whereas in Russia it can reach $900 \mathrm{~kg}$.

Today Kuzbass produces $56 \%$ of Russian coal, including $74 \%$ of coking coal. The total resources of Kuzbass coal is estimated to be 631 billion tons, including about 248 billion tons of coking coal. Total explored coal reserves comprise 130 billion tons, of which nearly 12 billion tons are located within the mine fields of existing enterprises. About $40 \%$ of the coal mined in Kuzbass is exported, which determines industry's strong dependence on the world fuel prices. 
However, increasing environmental burden, primarily due to the work of coal enterprises, has set the task of determining the limits of further expansion of coal extraction which is followed by irreversible critical changes in the environment.

According to the research conducted by the scientists of St. Petersburg State Mining University, who developed the program "Assessing the Environmental Capacity of the Kemerovo Region Natural Environment in light of the Prospects of the Coal Industry Development up to 2020 in the Structure of the Productive Forces of the Region," it is established that the current state of the intensive coal mining areas testifies the exhaustion of the ecological capacity of the natural environment. The anticipated increase in the ecological stress by 2020 will cause about $60 \%$ of the Kemerovo region territory (with the

Further expansion of coal production is only possible with applying the recommended methods of extraction and advanced processing of coal, processing coal refuse, capture and use of methane, wastewater treatment technologies at operating enterprises and those being designed. The expansion also requires strengthening the demands on dead pit abandonment, rehabilitation of mine sites and waste disposal.

Environmental problems make the need for ecologically oriented production and ecological education rather essential [11]. During the last several years, production and consumer waste in the Kemerovo region has been increasing annually by $6-8 \%$ a year on average. First of all, this results from the growing rates of coal mining, which exceeded 240 million tons in 2017. Currently, the volume of waste generation in coal mining exceeds 1.3 billion tons per year, which is more than $98 \%$ of the total waste generated in the region.

According to the statistics, in the Kemerovo region, about $0.7 \%$ of the total land area has been disrupted, which is significantly higher than the figure for Russia on the whole $(0.07 \%)$. However, within the territories of some municipalities, the percentage of disturbed land exceeds the all-Russian one by several hundred times. For example, for Kiselevsk and Prokopyevsk it comprises $27 \%$ and $19 \%$ respectively. The share of coal enterprises of the total area of disturbed land accounts for almost $84 \%$ (about 52 thousand hectares). Besides, the quality of recultivation is unsatisfactory. The area of annually remediated land is less than the area of land disturbed in the same period.

The extractive economy, as well as a significant amount of industrial production, has caused the severity of environmental problems. Among the regions of the Siberian Federal District, the Kemerovo region has one of the worst ecological indices. Only several indices of Krasnoyarsk and Irkutsk Regions are inferior, however, the anthropogenic load intensity per unit area of the Kemerovo region is higher.

Near Mezhdurechensk, Kemerovo, and Novokuznetsk the level of water pollution in the river Tom is unalterably high. The Tom and its tributaries are and in the foreseeable future will remain the main sources of water supply for most of the population of the region and at the same time a natural receiving stream for industrial, sanitary and agricultural wastewater.

Lately the level of air pollution in Kuzbass has been very high as well. In the Annual President's Message to the Federal Assembly of the Russian Federation (2018) President Putin mentioned Novokuznetsk as one of the most polluted cities in Russia. One inhabitant of the Kemerovo region accounts for almost 450 kilograms of repugnant substance in the atmosphere per year, and up to 2.5 tons of polluting emissions per Novokuznetsk residents.

The energy industry is considered to be a technologically connected aggregate of generating, network, sales companies of various types of property. Despite the ongoing processes of dividing business into various types and creating new market elements, the technological unity of the energy sector must be preserved. In the Kemerovo region, the preparation of technological shifts capable of increasing the stability of the region's economy is associated mainly with the ways of using coal and manufacturing high surplus value products. These directions, inherent in advancing to a new technological level, can be grouped as follows: 
1. Converting Russian combined heat and power plants with coal infrastructure from natural gas to coal. This will help increase the supply of coal by 30 million tons per year, provide sales, raise the regional budget revenue, develop the basic coal industry as well as social stability, and strengthen the country's energy security by increasing the share of coal in energy production. There are 27 power plants located in the western part of Russia that are designed to work with both coal fuel and natural gas.

2. Reconstructing the existing thermal power plants and constructing new ones. Creating new power generating plants should be carried out with the implementation of effective coal technologies which will result in reducing emissions. Special attention should be paid to technologies aimed at using uninflammable, long-flame and gas coals of the Kuznetsk basin. Reconstruction of generating capacities can be undertaken with the use of clean coal technologies and advanced technologies of utilizing methane emitted into the atmosphere during mining. This approach will also improve generating efficiency. In the Kemerovo region, an underground coal gasification project has been developed. It implies constructing eight enterprises with total electric capacity of 1,000 MW and heat energy overall production of about 10 million Gcal.

3. Implementing combined generation of heat and electricity into boiler houses. Historically, almost $50 \%$ of heat energy in the Kemerovo region is supplied by municipal and departmental boiler houses. Nowadays, eighty boiler houses in the region generate both heat and electricity. Completing the project will result in increasing the output up to 750 million $\mathrm{kWh}$ as well as decreasing heat energy production costs (by about 15\%). The main goal of the project is providing cheaper energy resources and obtaining more freedom from energy monopolies. Upon modernization of one existing boiler house, a kilowatt of installed capacity costs approximately $\$ 500$. For a new boiler house, one kilowatt of power capacity costs $\$ 900-1100$. Producing combined thermal and electric makes $90 \%$ of fuel utilization factor highly achievable. This figure is almost $30 \%$ higher than the one for existing boiler houses.

4. Increasing BTU content of coal and reducing its negative impact on the environment. Increasing the quality and calorific capacitance of coal is achieved, first of all, by removing the ballast, namely mineral inclusions and moisture. The next stage is utilizing sulfur and nitrogen oxides which are the components of flue gases. For example, 122,000 tons of sulfur and 21,000 tons of nitric acid can be extracted from flue gases containing oxides during a year of operation of a $500 \mathrm{MW}$ boiler unit (using coal containing 1\% of sulfur). Therefore, it is advisable to combine coal CHPPs and boiler-houses with equipment for coal gasification as well as utilization of sulfur, nitrogen, carbon, and mineral fertilizers extracted from flue gases. Applying the technology of converting sulfur and nitrogen oxides into acids is promising for the development of energy chemical complexes and their link to the locations of coal and raw materials deposits (phosphates, phosphorites, etc.) for the production of mineral fertilizers.

5. Applying pulverized coal-fired steam boiler with circular furnace and the system of stage coal combustion to power plants with generating capacity of 500-800 MW. These solutions provide significant increase in the efficiency of combusting coal fuel, reduce the environmental pressure. Besides they result in decrease in dimensions of technological equipment by $30-40 \%$ compared with those currently used. The system of stage coal combustion was introduced at Ekibastuz GRES 2 - Coal Power Plant, at the power plants in Poznan and Lublin (Poland). These systems were tested and implemented at Novoirkutsk TPP (Irkutsk, Russia) in the case of brown coal combustion. Tests proved the efficiency of the boiler of $93 \%$, no slag when burning slagging coals, steady ignition, and a low level of nitrogen oxides. 


\section{Conclusion}

The listed directions can become a source of further social and economic development of the Kemerovo region. However, one should not underestimate the possibility of increasing the economy efficiency as a result of productivity growth. At present, the dynamics of economic development proclaims the continuingly high mono-dependence of the regional economy and introduces the tasks which should be addressed by both the authorities and businesses cooperatively.

Problems of financial security illustrate the lack of financial resources, both for the regional budget and for business. According to the calculations, the level of financial security in the Kemerovo region is extremely low. In our opinion, calculations conducted on the basis of the proven methodology do not present the full picture of the financial security level. In particular, the region financial security is considered to be in the crisis zone judging by such financial security criteria as the ratio of the consolidated budget expenditures to GRP, the ratio of accounts payable to GRP, and the ratio of the balanced financial result of organizations to GRP.

In the Kemerovo region the problems of financial, energy and food security as well as the problems of the extractive economy are still urgent, but there are reasons to suppose that they are not critical. The calculations more likely show the qualitative side of the situation. The methodology of studying and mathematizing the research requires improvement taking into account realities of crisis phenomena/ the phenomena of crisis. Management of such key factors of influence as energy will bring the regional economy to a new more diversified and sustainable level.

\section{References}

1. D. Gros, F. Mustilli, The effects of sanctions and counter-sanctions on EU - Russian trade flows (CEPS, Brussels,2016)

2. Z. Kutlina-Dimitrova, Chief Economist Note, 3, 96-105 (2015)

3. EC Council, 2017. URL: http://www.consilium.europa.eu/en/policies/sanctions/

4. J. S. Hacker, G. A. Huber, Ph. Rehm, M. Schlesinger, R. Valletta, The Rockefeller Foundation, 6 (2010)

5. J. G. Fernald, C. I. Jones, American Economic Review, 104(5), 44-49 (2014)

6. J. S. Hacker, G. A. Huber, A. Nichols, Ph. Rehm, S. Craig, The Rockefeller Foundation, 6 (2012)

7. IEA/OECD, World Energy Outlook (EUCL, Paris, 2013)

8. F. J. Andréa, S. Smuldersb, European Economic Review, 69, 18-39 (2014)

9. S. Voigta, E. De Cianb, M. Schymuraa, E. Verdolinic, Energy Economics, 41, 47-62 (2014)

10. I. A. Kudryashova, N. V. Zakharova, E. I. Kharlampenkov, E3S Web Conf., 21, 02016 (2017)

11. M.A. Gasanov, K.A. Kolotov, K.A. Demidenko, E.A. Podgornaya, O.V. Kadnikova, IOP Conf. Ser.: Earth Environ. Sci., 50:1, 012025 (2017) 